\title{
No Alteration in Serum Leptin Levels during Acute Endotoxemia in Sheep
}

\author{
Mohamed SOLIMAN ${ }^{1,2)}$, Shawky ABDELHADY ${ }^{2)}$, Ibrahem FATTOUH ${ }^{2)}$, Katsumi ISHIOKA ${ }^{1)}$, Hiroshi KITAMURA ${ }^{1)}$, \\ Kazuhiro KIMURA ${ }^{1)}$ and Masayuki SAITO ${ }^{1) *}$
}

${ }^{1)}$ Laboratory of Biochemistry, Department of Biomedical Sciences, Graduate School of Veterinary Medicine, Hokkaido University, Sapporo 060-0818, Japan and ${ }^{2)}$ Department of Biochemistry \& Physiology, Faculty of Veterinary Medicine, Tanta University, Egypt

(Received 11 April 2001/Accepted 25 June 2001)

ABSTRACT. To determine the role of leptin in endotoxin-induced anorexia in ruminants, circulating leptin levels were measured during acute experimental endotoxemia in sheep. Injection of bacterial lipopolysaccharide ( $450 \mathrm{ng} / \mathrm{kg}$, i.v.) induced anorexia accompanied with fever and increases in serum levels of cortisol, insulin and glucose which are known to stimulate leptin secretion in rodent and human, while it did not affect serum leptin levels at all. These results indicate that serum leptin levels in sheep during acute endotoxemia are differentially regulated from those in rodent and human, and that leptin might not be involved in the endotoxin-induced anorexia in sheep. KEY WORDS: leptin, LPS, ovine.

J. Vet. Med. Sci. 63(10): 1143-1145, 2001

Bacterial infection is a major cause for management damage of live-stock animals. In gram negative bacteria, lipopolysaccharide (LPS) is an inducer of inflammatory response. During experimental endotoxemia, animals given LPS suffer fever and anorexia probably due to production of interleukin (IL)-1 and other cytokines. Leptin, the product of the $o b$ gene, is a cytokine secreted by adipocytes. It is a potent satiety factor and also involved in the regulation of autonomic and gonadal functions [7, 9]. Circulating leptin levels are well correlated with body fat content, and influenced by various neuroendocrine factors such as insulin, glucocorticoids and catecholamines. Since in rodents LPS injection causes an increase of plasma leptin levels, leptin has been suggested to be involved in endotoxin-induced anorexia $[6,8,11]$.

The regulation of food intake and nutrient metabolism in ruminants is known to be considerably different from those in non-ruminant species. However, at least with regard to leptin, quite similar properties have been reported in ruminants and non-ruminant species $[1,5]$. In fact, recombinant ovine leptin, as well as murine leptin, acts as an anorexigenic peptide when given intracerebroventricularly [2]. Thus, it is possible that leptin may be involved in anorexia during early phase of inflammation in ruminants, too. To test this hypothesis, we determined serum leptin levels in sheep after LPS treatment.

Ten female sheep (6-9 months old), weighing 21-36 kg, were kept free access to food and water and handled daily for 2 weeks prior usage to avoid handling stress. One week before the experiment a sterile catheter was fixed on the jugular vein for blood sampling. On the day of experiment they were divided into two groups (five in each) and injected intravenously with either LPS (Esherichia coli 055:B5, Difco, Detriot, MI, U.S.A.) at a dose of $450 \mathrm{ng} / \mathrm{kg}$ body weight or saline as a control, respectively. Blood was col-

\footnotetext{
* Correspondence to: Saito, M., Laboratory of Biochemistry, Department of Biomedical Sciences, Graduate School of Veterinary Medicine, Hokkaido University, Sapporo 060-0818, Japan.
}

lected and rectal temperature was monitored at appropriate time intervals for $12 \mathrm{hr}$. Food intake was measured by placing preweighted green fodder and silage and weighing the uneaten at $8 \mathrm{hr}$ after the injection. All experimental procedures were in accordance with the guideline of the animal use regulation of Hokkaido University and also with that of Tanta University.

Serum was separated by centrifugation and stored at $-80^{\circ} \mathrm{C}$ until assay. Serum cortisol and insulin concentrations were measured using respective RIA kits for human cortisol (Amerlix Cortisol RIA kit, Amersham Corp, Arlington Heights, IL,. U.S.A.) and insulin (Eiken Chemical Co., Tokyo). Serum glucose levels were measured using COBAS MIRA, based on the kit supplied by Nippon Roche (Tokyo). Serum leptin levels were measured using multispecies leptin RIA kit (LINCO Research Inc., St. Charles, MO, U.S.A.) as reported previously [5]. All data are represented as means \pm SEM and analyzed by Dunnett's $t$-test for multiple comparisons.

Sheep injected with LPS were tachypenic and recumbent with intermittent cough within an hour after LPS injection. They also developed anorexia and did not have any food during the experimental period, while sheep injected with saline ate $5.4 \pm 0.2 \mathrm{~kg}$ of fodder and silage. Rectal body temperature increased immediately after the injection and remained high for at least $4 \mathrm{hr}$ (Fig. 1). Thus it was confirmed that the LPS used in the present study effectively induced typical acute inflammatory symptoms, including anorexia, in sheep. However, the leptin level in the serum from these sheep was not changed for $12 \mathrm{hr}$, showing almost the same levels as those in saline-injected controls (Fig. 2). These results seem to contrast with those reported in rodents, where plasma leptin levels and leptin mRNA expression in adipose tissue are increased following LPS treatment $[6,8,11]$.

Plasma level of leptin is primarily dependent on its synthesis and secretion in adipocytes, which are under the influence of various neuroendocrine factors. Particularly, insulin 


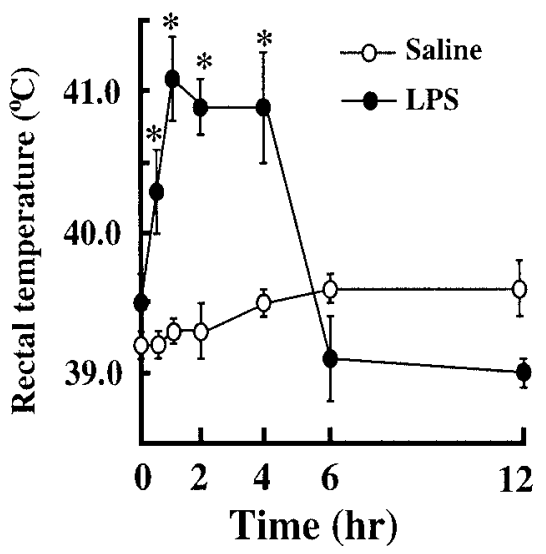

Fig. 1. Changes in rectal temperature after LPS injection in sheep. Either LPS (450 $\mathrm{ng} /$ $\mathrm{kg}$ body weight) or saline was injected intravenously at 9 a.m. (Time 0 ). Values are means \pm SEM for 5 sheep for each treatment. ${ }^{*} \mathrm{p}<0.05$ vs. saline control.

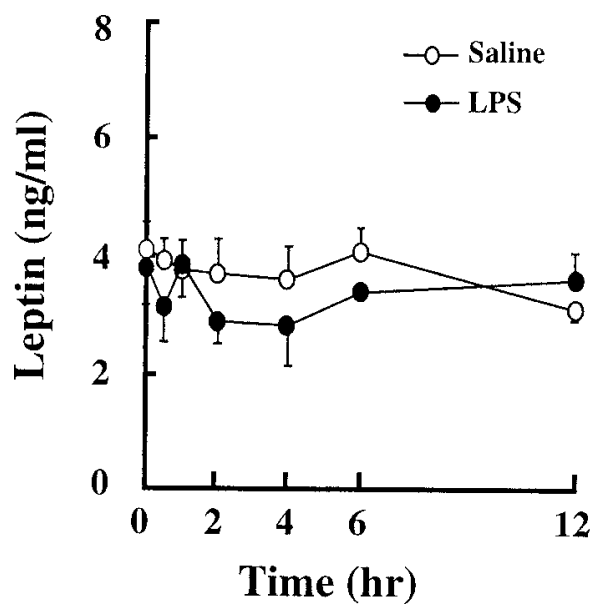

Fig. 2. Changes in serum leptin levels after LPS injection. LPS or saline was injected as in Fig.1. Values are means \pm SEM for 5 sheep for each treatment. $* \mathrm{p}<0.05$ vs. saline control.

and glucocorticoids are known as potent stimulators and catecholamines as suppressors [7, 9]. To examine possible involvement of these factors in the regulation of plasma leptin in sheep, we measured their serum levels after LPS injection. Insulin itself and glucose metabolism activated by insulin are suspected to play critical roles in the post-prandial rise of plasma leptin level in rodent and human [10, 12]. As shown in Fig. 3, in sheep LPS injection produced a significant rise in serum insulin level at 2-6 hr, which was accompanied with hypoglycemia. Despite such sustained hyperinsulinemia, leptin level was little changed. In addition to insulin, cortisol in the serum from LPS-injected
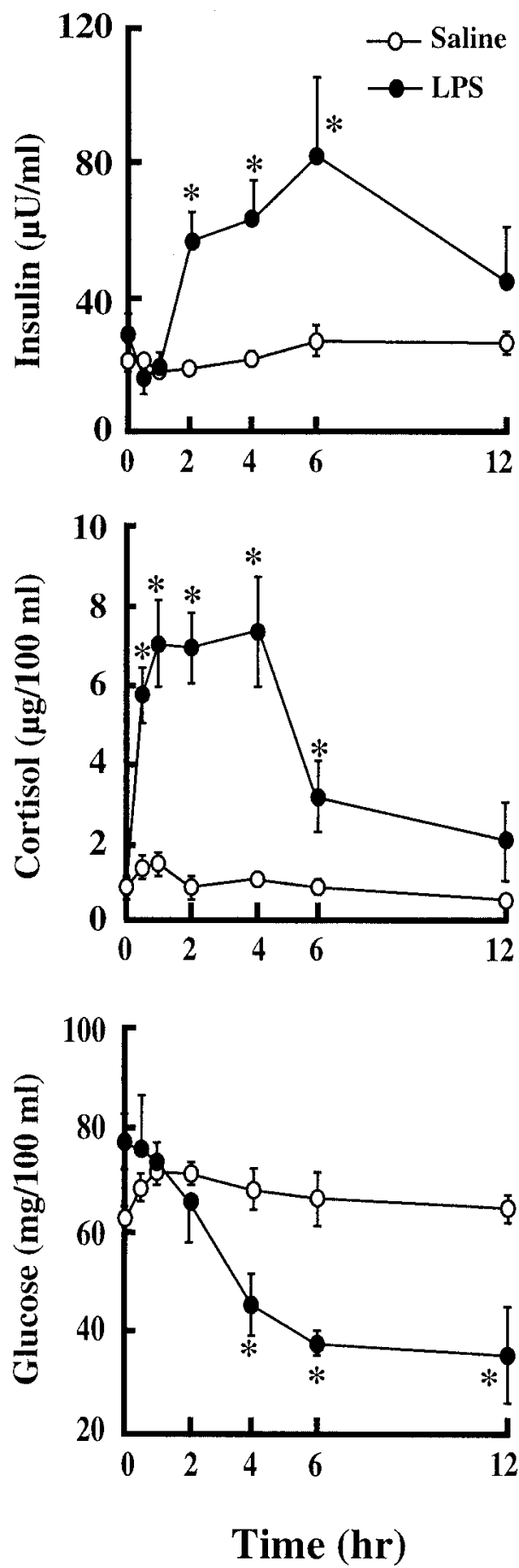

Fig. 3. Changes in serum insulin, cortisol and glucose levels after LPS injection. LPS or saline was injected as in Fig.1. Values are means \pm SEM for 5 sheep for each treatment. $* \mathrm{p}<0.05$ vs. saline control.

sheep was rapidly increased and sustained at much higher levels than saline-injected control until $6 \mathrm{hr}$ post-injection 
(Fig. 3). The rapid rise of plasma glucocorticoids after LPS administration is quite consistent with the previously reported results not only in rodents but also in live-stock animals including sheep [3, 4]. Since serum ACTH level is also increased after LPS injection [3], the increased cortisol would be due, at least in part, to adrenocortical activation. However, such adrenocortical activation induced by LPS had no effect on serum leptin level. Thus, unlike in rodent and human, in sheep no relation of plasma leptin level was found to plasma insulin and cortisol. These results suggest some regulatory mechanism and/or factors for leptin synthesis and secretion in sheep different from those in rodent and human. Alternatively, it seems also possible that some suppressive factors, such as catecholamines, may cancel the stimulatory effects of insulin and glucocorticoids on leptin production. At present, we have no information about serum catecholamine levels, but the above idea may be unlikely because the LPS-induced decrease in blood glucose level can be best explained by potent hypoglycemic action of insulin but not by hyperglycemic action of catecholamines. Thus, serum catecholamines, even if they are elevated, may not function effectively as anti-insulin factors in the present experimental conditions.

In summary, the present results showed no response of serum leptin to LPS administration in sheep. In preliminary experiments, we also observed similar results in Holstein cows. All these results collectively suggest that leptin synthesis and secretion in ruminants are regulated by some mechanisms largely different from those in rodent and human. Furthermore, it is also unlikely, at least in ruminants, that plasma leptin is involved in endotoxin-induced anorexia.

This work was supported by PROBRAIN from the Biooriented Technology Research Advancement Institution,
Japan, and Grants-in-Aid of Recombinant Cytokines Project (RCP 2001-4230) and of the investigation on the etiology and prevention of bovine mastitis (No. 2210) by the Ministry of Agriculture, Forestry and Fisheries of Japan.

\section{REFERENCES}

1. Blache, D., Tellam, R.L., Chagas, L. M., Blackberry, M. A., Vercoe, P. E. and Martin, G. B. 2000. J. Endocrinol. 165: 625637.

2. Clarke, I. J., Henry, B., Iqbal, J. and Goding, J.W. 2001. Clin. Exp. Pharmacol. Physiol. 28: 106-107.

3. Coleman, E. S., Elsasser, T. H., Kemppainen, R. J., Coleman, D. A. and Sartin, J. L. 1993. Neuroendocrinology 58: 111-122.

4. Dadoun, F., Guillaume, V., Sauze, N., Farisse, J., Velut, J.G., Orsoni, J.C., Gaillar, R. and Oliver, C. 1998. Eur. J. Endocrinol. 138: 193-197.

5. Delavaud, C., Bocquier, F., Chilliard, Y., Keisler, D. and Gertler, A. 2000. J. Endocrinol. 165: 519-526.

6. Francis, J., MohanKumar S. M. and MohanKumar, P. S. 2000. Brain Res. 867: 180-187.

7. Friedman, J. M. and Halaas, J. L. 1998. Nature (Lond.) 395: 763-770.

8. Grunfeld, C., Zhao, C. and Fuller, J. 1996. J. Clin. Invest. 97: 2152-2157.

9. Houseknecht, K. L., Baile, C. A., Matteri, R. L. and Spurlock, E. M. 1998. J. Anim. Sci. 76: 1405-1420.

10. Saladin, R., De Vos, P., Guerre-Millo, M., Leturque, A., Giaard, J., Staels, B. and Auwerx, J. 1995. Nature (Lond.) 377: 527-529.

11. Sarraf, P., Frederick, C. R., Turner, M., Ma, G., Jaskowiak., Rivet III, D., Flier, J., Lowel, B., Fraker, D. and Alexander, R. 1997. J. Exp. Med. 185: 171-175.

12. Wellhoener, P., Fruehwald-Schultes, B., Keren, W., Dantz, D., Kerner, W., Born, J., Fehm, H. and Peters, A. 2000. J. Clin. Endocrinol. Metab. 85: 1267-1271. 